\title{
Determination of soil permeability coefficient following an updated grading entropy method
}

Brendan C. O'Kelly MEngSC, PhD, FTCD, CEng, CEnv, MICE Associate Professor, Department of Civil, Structural and Environmental Engineering, Trinity College Dublin, Dublin, Ireland (corresponding author: bokelly@tcd.ie) (Orcid:0000-0002-1343-4428)
María Nogal MSc, MRes, PhD

Assistant Professor, Department of Materials, Mechanics, Management and Design, Faculty of Civil Engineering and Geosciences, Delft University of Technology, Delft, the Netherlands (Orcid:0000-0001-5405-0626)

This paper presents a critical review of the grading entropy approach of permeability-coefficient predictions $\left(k_{\mathrm{P}}\right)$ for coarse-grained soils. The approach applies the grading entropy theory to particle-size distributions (PSDs), such that the entirety of each gradation curve can be interpreted as a single point on a grading entropy chart, plotting its normalised entropy increment $(B)$ against relative base grading entropy $(A)$ values. Published data sets of measured permeability-coefficient $\left(k_{\mathrm{M}}\right)$ values for saturated compacted silty sand, sand and gravel materials are examined to understand the dependence of $A$ and $B$ on various gradation parameters and the void ratio (e). In particular, log $k_{\mathrm{M}}$ negatively correlates with $\log B$ and positively correlates with $\log A$ and $e(\log e)$. As such, power functions of the form $k_{\mathrm{P}}=C_{1} A^{C_{2}} B^{C_{3}} e^{C_{4}}$ prove statistically superior, noting that the fitting coefficient $C_{1}$ to $C_{4}$ values are specific to the PSD range and densification (compaction) states investigated for the permeability tests. Recommendations are given for increasing the predictive power, including separate models for well-graded and poorly graded materials and the addition of a particle shape factor and specific surface parameters in the regression correlation.

\begin{tabular}{|c|c|}
\hline \\
\hline \multicolumn{2}{|r|}{ relative base grading entropy } \\
\hline$B$ & normalised entropy increment \\
\hline$C_{1}$ to $C_{4}$ & $\begin{array}{l}\text { fitting coefficients for regression models }\left(C_{1}\right. \\
\left.(\mathrm{m} / \mathrm{s}) ; C_{2} \text { to } C_{4} \text {, dimensionless }\right)\end{array}$ \\
\hline$C_{\mathrm{C}}$ & coefficient of curvature \\
\hline$C_{\mathrm{U}}$ & coefficient of uniformity \\
\hline$D_{10}$ & effective grain size (mm) \\
\hline$D_{30}, D_{50}, D_{60}$ & $\begin{array}{l}\text { particle sizes corresponding to } 30,50 \text { and } 60 \% \\
\text { dry mass passing, respectively }(\mathrm{mm})\end{array}$ \\
\hline$e$ & void ratio \\
\hline$e_{\text {compacted }}$ & void ratio of compacted specimens \\
\hline$G_{\mathrm{C}}$ & characteristic gradation parameter (mm) \\
\hline$k$ & coefficient of permeability (m/s) \\
\hline$k_{\mathrm{M}}$ & measured permeability coefficient $(\mathrm{m} / \mathrm{s})$ \\
\hline$k_{\mathrm{P}}$ & predicted permeability coefficient (m/s) \\
\hline$m$ & number of sample subdivisions (fractions) \\
\hline$n$ & number of data points (observations) \\
\hline$p$ & $p$-value of statistical hypothesis testing \\
\hline$R^{2}$ & coefficient of determination \\
\hline$R_{\mathrm{a}}^{2}$ & adjusted coefficient of determination \\
\hline$x_{i}$ & relative frequency of fraction $i$ \\
\hline
\end{tabular}

\section{Introduction}

The topic of accurate prediction of soil permeability is of importance to geotechnical engineers and researchers. The coefficient of permeability $(k)$, defined as the mean discharge velocity of the fluid flow through a porous medium for a unit hydraulic gradient, is principally dependent on the size and connectivity of the pore voids, which are related to the size distribution and shape of the solid particles, the degree of saturation, soil structure and the pore fluid's viscosity. As customary, reported laboratory $k$ values typically correspond to the soil in its saturated state and for a standardised permeant temperature of $20^{\circ} \mathrm{C}$ since fluid viscosity is temperature dependent.

Direct measurement using well pumping, borehole slug and tracer tests and laboratory constant- and falling-head permeameter approaches typically involve relatively high economic cost, are time-consuming and require specialised facilities and expertise (O'Kelly, 2008, 2009, 2016), such that they are often not considered viable options for many projects. The same often applies for indirect measurement approaches, including the calculation of laboratory $k$ values from consolidation parameters determined from oedometer, consolidometer and hydraulic consolidation testing (O'Kelly, 2005, 2006).

At the feasibility stage of large projects or for the design of drainage, soak wells, septic tanks and so on, geotechnical engineers are often needed to provide estimated (mainly for budget constraints) soil permeability. Such assessments are often made by way of empirical index-property-based formulae - for example, considering soil gradation, volumetric characteristics, bulk density, clay content and organic content. Dozens of empirical correlations (models) have been proposed over the decades in order to correlate the $k$ value of a soil sample with some representative particle size from its gradation curve, usually taken as the effective grain size $\left(D_{10}\right)$ or mean particle size $\left(D_{50}\right)$ index values - that is, the particle sizes corresponding to 10 and $50 \%$ dry mass passing, respectively. The void ratio $(e)$ is long recognised as a primary predictor of soil permeability-coefficient values and is included in many empirical and semi-empirical models (e.g. Carman, 1937, 1939; Carrier, 2003; Chapuis, 2004, 2012; 
Chapuis and Aubertin, 2003; Kozeny, 1927). Some of the most popular correlations, which are primarily based on some representative particle size(s), gradation parameter, void ratio and/or specific surface of the solids, are presented in the papers by Arshad et al. (2019) and Chapuis (2012), along with their intended applications in terms of soil types, gradation ranges and density states.

Recently, approaches based on the grading entropy framework (attributed to Lörincz's doctoral thesis (Lörincz, 1986; Lörincz et al., 2017; Singh, 2014)) and the characteristic gradation parameter (Arshad et al., 2019) have been proposed for permeability assessments of coarse-grained soils. The primary focus of the present investigation is on the grading entropy approach. The characteristic gradation parameter $G_{\mathrm{C}}$ (Equation 1) approach is mentioned at this stage for completeness and has been employed in the model given by Equation 2 for predictions of the saturated permeability-coefficient $\left(k_{\mathrm{P}}\right)$ value for sand and silty sands.

1. $G_{\mathrm{C}}=0 \cdot 3 D_{10}+0 \cdot 2 D_{30}+0 \cdot 3 D_{50}+0 \cdot 2 D_{60}$

where $D_{10}, D_{30}, D_{50}$ and $D_{60}$ are the particle sizes, given in millimetres, for $10,30,50$ and $60 \%$ dry mass of material passing, respectively.

2. $k_{\mathrm{P}}(\mathrm{m} / \mathrm{s})=\left(e \sqrt{G_{\mathrm{C}}}\right)^{6 \cdot 7} \quad($ Arshad et al., 2019)

\section{Literature review}

The grading entropy approach applies entropy theory (Shannon, 1948) to the particle-size distribution (PSD) of a granular mixture, thereby establishing a vectorial depiction of gradation variation (McDougall et al., 2013) arising from an ongoing change in the PSD (because of grain crushing or soil erosion) or for materials with different PSDs - that is, each grading curve can be interpreted and plotted as a discrete point in the grading entropy chart, whose coordinates $A$ (relative base grading entropy) and $B$ (normalised entropy increment) are computed according to the following equations

3. $A=\frac{\sum_{i=1}^{m} x_{i}(i-1)}{m-1}$

4. $B=-\frac{\sum_{i=1}^{m} x_{i} \log _{2} x_{i}}{\log _{\mathrm{e}} m}$

where $m$ is the number of fractions (sample subdivisions) and $x_{i}$ is the relative frequency of fraction $i$.

Imre et al. (2012) explained that the variation in fraction number $m$ for soils with different PSDs can induce a discontinuity in the normalised entropy path. As described by Feng et al. (2019a), in order to remove this discontinuity, 'zero' fractions (i.e. coarser or finer fractions with zero particle frequency), which leave the nonnormalised grading entropy unaffected, are introduced in the analysis (see the paper by Imre et al. (2012)). Based on the normalised grading entropy equations, for a certain fraction number $m$, the maximum normalised entropy increment $(B)$ curve is fixed (see the calculation process in the book by Singh (2014)); however, with different fraction numbers $m$, the variation of the maximum $B$ curve is rather unnoticeable (cf. the paper by Imre et al. (2008)).

As demonstrated in Figure 1, variations in different materials' gradations can be conveniently recorded using this approach in terms of discrete points presented in the one chart, rather than their usual presentation as a family of PSD curves. As explained in the paper by McDougall et al. (2013) and also evident from examination of the various PSD plots presented in this figure, the coordinate $A$ reflects the skewness (symmetry) of a PSD curve, while the coordinate $B$ measures its peakiness (kurtosis). For instance, with coordinate $A$ decreasing from unity to 0.5 and increasing values of coordinate $B$, the proportion of smaller-sized particles in the soil mass increases, which is associated with lower $k_{\mathrm{M}}$ values.

A perceived advantage of the grading entropy permeabilityprediction models is that through the coordinates $A$ and $B$, they account for the entire soil gradation, rather than considering some representative particle size (e.g. $D_{10}$ or $D_{50}$ value) of the grading curve, as employed in many of the other empirical index-propertybased formulae. The model given by Equation 2 also has this advantage since the philosophy of the characteristic gradation parameter $G_{\mathrm{C}}$ is to embody the entirety of the soil gradation curve.

Recent studies by Feng et al. (2018a, 2018b, 2019a) on various gravel mixtures and Arshad et al. (2019) on various sands and silty sands investigated the grading entropy coordinates $A$ and $B$ for predictions of the $k_{\mathrm{P}}$ value. The premise of the studies by Feng et al. (2018a, 2018b, 2019a) was that pavement engineers often specify gradation curve envelopes when designing gravel mixtures, such that a method of estimating the permeabilitycoefficient value straight from the gradation curve is useful. Specifically, they performed multiple linear regression analyses, producing Equations 5-7 from data sets of measured permeability coefficient $\left(k_{\mathrm{M}}\right)$ for asphalt concrete (Feng et al., 2018a), various saturated $10 \mathrm{~mm}$ crushed basalt-gritstone gravel mixtures (Feng et al., 2019a) and a database of 164 hydraulic conductivity tests for various sands and gravels compiled from ten earlier publications summarised in the paper by Feng et al. (2018b).

$$
\begin{aligned}
& k_{\mathrm{P}}(\mathrm{m} / \mathrm{s})=8.4 \times 10^{-4} A^{11.71} B^{-2.73} \\
& \left(R^{2}=0 \cdot 20, p<0 \cdot 001, n=1578\right)
\end{aligned}
$$

5. (Feng et al., 2018a) 


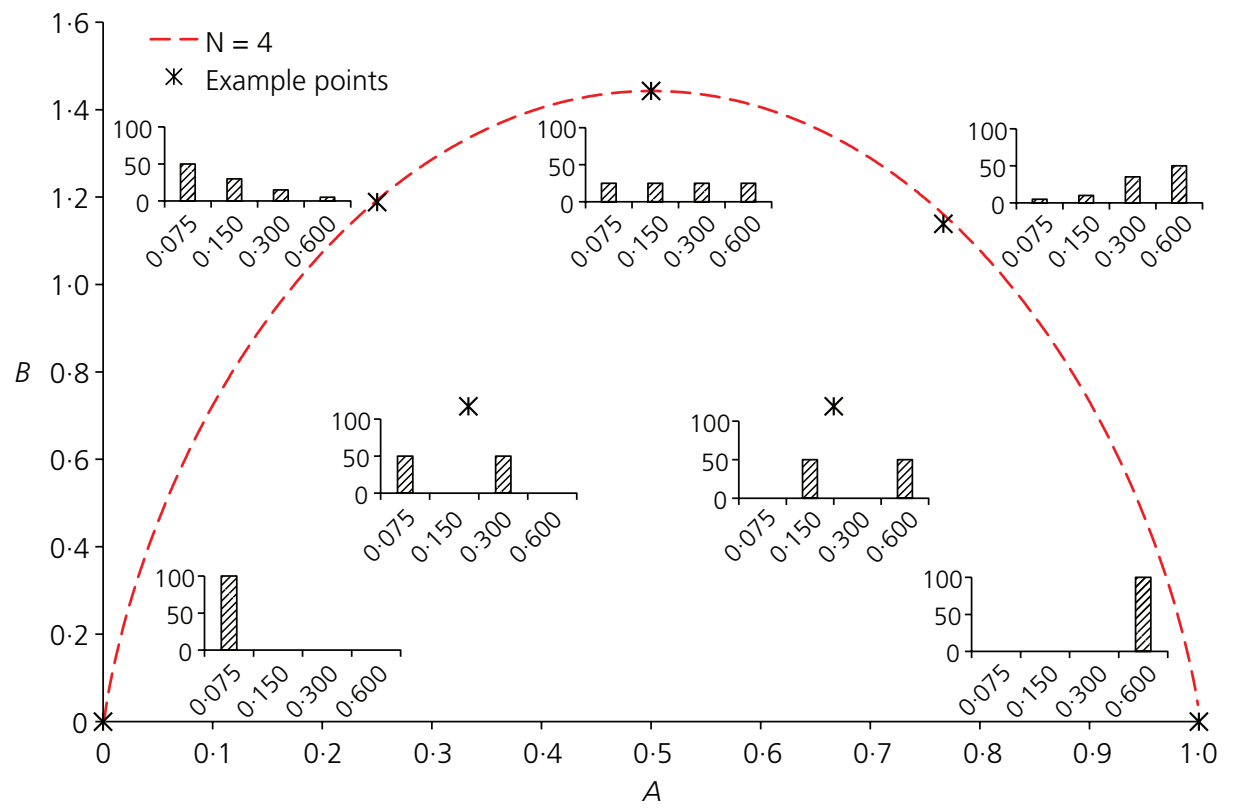

Figure 1. Effect of gradation changes on the grading entropy coordinates $A$ and $B$ (from the paper by Feng et al. (2019a) and originally based on the paper by McDougall et al. (2013))

$$
\begin{aligned}
& k_{\mathrm{P}}(\mathrm{m} / \mathrm{s})=1.4547 \times 10^{-1} A^{8.90} B^{-2.30} \\
& \left(R^{2}=0 \cdot 90, p<0 \cdot 0001, n=30\right)
\end{aligned}
$$

6. (Feng et al., 2019a)

$$
\begin{aligned}
& k_{\mathrm{P}}(\mathrm{m} / \mathrm{s})=4 \cdot 704 \times 10^{-2} A^{6 \cdot 04} B^{-0 \cdot 34} \\
& \left(R^{2}=0 \cdot 69, p<0 \cdot 0001, n=164\right)
\end{aligned}
$$

7. (Feng et al., 2018b)

where $n$ is the number of data points (observations); $p$ refers to the $p$-value of the statistical hypothesis testing; and $R^{2}$ is the coefficient of determination.

As per Equations 5-7, Feng et al. (2018a, 2018b, 2019a) found that compared with other possible formulations, power functions of the form $k_{\mathrm{P}}=C_{1} A^{C_{2}} B^{C_{3}}$ are statistically superior; where $C_{1}$, $C_{2}$ and $C_{3}$ are the fitting coefficients. Note that $C_{1}$ is expressed in the same units as $k_{\mathrm{P}}$, whereas $C_{2}$ and $C_{3}$ are dimensionless. This avoids the mathematical and physical inconsistencies discussed by Castillo et al. (2014a, 2014b).

The study presented by Arshad et al. (2019) employed essentially the same approach, investigating saturated standard Proctor (SP)compacted sand and silty sand samples. Based on their published data, the authors derived the following equation as part of the present investigation

$$
k_{\mathrm{P}}(\mathrm{m} / \mathrm{s})=7.52 \times 10^{-4} A^{4 \cdot 66} B^{-3.88}
$$

8. $\left(R^{2}=0 \cdot 29, p=0 \cdot 09, n=17\right)$

As described earlier, the $k_{\mathrm{M}}$ value is principally controlled by the size and connectivity of the pore voids, which are dependent on the shape and size distribution of the constituent solids, whether well graded or poorly graded, the void ratio and the soil structure. As such, models of the form given by Equations 5-8 have potential shortcomings, most notably since they do not account for the soil densification level (packing state) or particle shape - that is, although dependent on gradation (and hence coordinates $A$ and $B$ ) and to a lesser extent on the particle shape, the placement void ratio is also strongly dependent on the densification level (packing state). For a given soil material, an equation of the form $k_{\mathrm{P}}=C_{1} A^{C_{2}} B^{C_{3}}$ produces the same $k_{\mathrm{P}}$ value for loose, medium and dense packing states and for particle shape classes as diverse as irregular to rounded, which are clearly not the cases. As such, relationships of the form $k_{\mathrm{P}}=f_{\mathrm{n}}(A, B, e)$ should prove statistically superior and extend the model's scope and reliability (Feng et al., 2019b). This is analogous to the approach employed for Equation 2, where the $G_{\mathrm{C}}$ and $e$ parameters account for gradation characteristics and packing state, respectively. The packing state is controlled to some degree by the particle shape, such that the controlling effect of the latter on the permeability-coefficient magnitude is partially accounted for by the inclusion of the $e$ parameter in the model.

Further, from inspection of Equations 6-8 for sand and gravel materials, the values of the coefficients $C_{1}$ to $C_{3}$ are significantly 
different between equations. Feng et al. (2018b) explained that this may be due to the diversity of gradation ranges and mineralogical compositions of the various sand and gravel materials considered in their study, compared with the $10 \mathrm{~mm}$ basalt-gritstone gravel mixtures investigated in another paper by the same authors (Feng et al., 2019a), which is undoubtedly the case. In other words, the fitting-coefficient values in Equations 5-8 pertain to the particle shape and the gradation and densification (compaction) ranges of the materials investigated for the permeability tests, consistent with the fact that the different samples (data sets) considered in the papers by Feng et al. (2018a, 2018b, 2019a) and Arshad et al. (2019) did not represent the same statistical population - that is, like any empirical correlation, Equations 5-8 cannot be applied with confidence for materials having different physical characteristics, prepared at other densification levels and (or) outside their calibration gradation ranges.

As evident from Figure 2, compared with the gravel and sand materials for Equations 6 and 7, the power function given by Equation 8 for the sand and silty sand materials predicts substantially lower $k_{\mathrm{P}}$ values. In this figure, the domain for each presented model is based on its reported range of $k_{\mathrm{M}}$ or coordinate $A$ and $B$ values, as

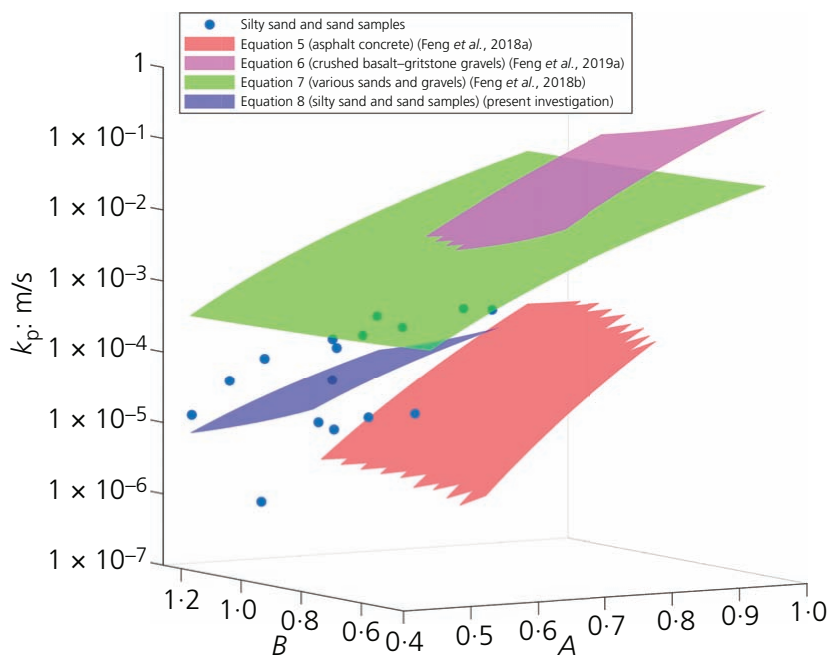

Figure 2. Comparison of various grading entropy permeabilityprediction models. Note that the green three-dimensional domain (Equation 7) does not cover the entire calculated $k_{\mathrm{p}}$ range, because the represented ranges of $A$ and $B$ do not produce such a wide range of $k_{\mathrm{p}}$ values listed in Table 1. The spatial trend given by these three models over their calibration permeability-coefficient ranges is consistent with the expected reduction in $k$ values for reducing particle size from gravel to sand to silty sand materials. On this basis, it would appear a step too far for a single regression correlation of the form $k_{\mathrm{P}}=C_{1} A^{C_{2}} B^{C_{3}}$ to give a satisfactory assessment of $k$ values for a broad spectrum of coarse- and (or) fine-grained soils. This is undoubtedly the case when different densification levels are considered.

The present investigation provides in-depth evaluation of the grading entropy approach for permeability-coefficient assessments. To this aim, two previously published data sets are combined and analysed namely, for 30 saturated compacted basalt-gritstone gravel mixtures $\left(k_{\mathrm{M}}=4.2 \times 10^{-3}\right.$ to $\left.5.6 \times 10^{-1} \mathrm{~m} / \mathrm{s}\right)$ presented in the paper by Feng et al. (2019a) and for 20 saturated SP-compacted fine and coarse silica sand and silty sand samples $\left(k_{\mathrm{M}}=7.2 \times 10^{-7}\right.$ to $5.6 \times$ $10^{-4} \mathrm{~m} / \mathrm{s}$ ) presented in the paper by Arshad et al. (2019). Hereafter, these sources are referred to as data sets X and Y, respectively. From a review of the pertinent literature, these two papers are presently the only ones that report values of the coordinates $A$ and $B$ along with pertinent gradation parameter, void ratio and measured permeabilitycoefficient values (determined from standard laboratory constant-head permeameter testing) for the investigated soils.

In particular, the dependence of the grading entropy coordinates $A$ and $B$ on the coefficient of uniformity $\left(C_{\mathrm{U}}\right)$, coefficient of curvature $\left(C_{\mathrm{C}}\right), D_{10}, D_{50}$ and compacted void ratio $\left(e_{\text {compacted }}\right)$ is closely examined. From a practical application point of view, relative density is usually estimated for subsurface soil strata by various means of field tests (i.e. cone penetration test, standard penetration test etc.) and also compaction specifications for earthwork verification are generally defined by a dry density ratio of 95 or $98 \%$ of maximum dry density (modified compactive effort). Neither of the data sets $\mathrm{X}$ and $\mathrm{Y}$ reported the maximum and minimum void ratio values for the various materials examined - that is, only $e_{\text {compacted values were }}$ given, such that it was not possible to perform analysis and evaluations based on the relative density and (or) at a particular dry density ratio, which would have been preferable.

None of the previous grading entropy investigations has explicitly considered the importance of soil gradation in terms of whether the materials were well graded or poorly graded and its impact on deduced correlations. Presumably, it was assumed that this aspect was incorporated in the coordinates $A$ and $B$ values. However, it is the

Table 1. Calibration ranges in terms of the measured permeability coefficient or coordinates $A$ and $B$ for various grading entropy permeability-prediction models

$\begin{array}{lcccc}\text { Equation (model) } & \boldsymbol{A} & \boldsymbol{B} & \boldsymbol{k}_{\mathbf{M}} \mathbf{\text { m}} \mathbf{s} & \text { Reference } \\ \text { Equation 5 } & \text { Not reported } & \text { Not reported } & 2.0 \times 10^{-6} \text { to } 3.8 \times 10^{-4} & \text { Feng et al. (2018a) } \\ \text { Equation 6 } & 0.64-0.94 & 0.46-1.01 & 4.2 \times 10^{-3} \text { to } 5.6 \times 10^{-1 a} & \text { Feng et al. (2019a) } \\ \text { Equation 7 } & \text { Not reported } & \text { Not reported } & 1.0 \times 10^{-6} \text { to } 6.0 \times 10^{-1 b} & \text { Feng et al. (2018b) } \\ \text { Equation 8 } & 0.44-0.72 & 0.85-1.26 & 7.2 \times 10^{-7} \text { to } 5.6 \times 10^{-4 c} & \text { Arshad et al. (2019) }\end{array}$

\footnotetext{
a Data set $X$ in the present investigation

${ }^{\mathrm{b}}$ Computed from the measured intrinsic permeability range reported by Feng et al. (2018b)

${ }^{c}$ Data set $Y$ in present investigation
} 
authors' opinion that correlations with greater statistical significance would be obtained for considering well-graded and poorly graded materials as separate groupings. This aspect is investigated for each of the parameters $C_{\mathrm{U}}, C_{\mathrm{C}}, D_{10}, D_{50}$ and $e_{\text {compacted. }}$

Based on new insights gleaned from the detailed analysis of the combined $\mathrm{X}$ and $\mathrm{Y}$ data sets, improved grading entropy soil permeability-prediction models are proposed and evaluated. Further, whereas the studies reported in the papers by Feng et al. (2018a, 2018b, 2019a) considered sand and gravel materials as well as asphalt concrete, one of the novelties of this paper is the extension of the grading entropy approach for permeability assessments of silty sand materials.

\section{Analysis and discussion of published data}

\section{Grading entropy coordinates}

The widely different gradations of 30 gravel mixtures $\left(D_{10}=\right.$ $0 \cdot 72-7.02 \mathrm{~mm}$ and $\left.D_{50}=2 \cdot 17-9.93 \mathrm{~mm}\right)$ and 17 sandy soil samples $\left(D_{10}=0.01-0.42 \mathrm{~mm}\right.$ and $\left.D_{50}=0.02-0.56 \mathrm{~mm}\right)$ comprising data sets $\mathrm{X}$ and $\mathrm{Y}$, respectively, are shown using the grading entropy chart in Figure 3. Note that from the authors' preliminary analysis of the $n=20$ data entries comprising data set $\mathrm{Y}$, unresolvable inconsistencies were found for the data entries corresponding to the three soil samples listed as $\mathrm{A}, \mathrm{B}$ and $\mathrm{A}_{50}+$ $\mathrm{C}_{50}$ in the paper by Arshad et al. (2019). For this reason, the authors considered it prudent to omit these three soils from statistical analysis reported in the present investigation.

The $A$ coordinate values for all investigated soils ranged from 0.44 to 0.94 - that is, the grading entropy coordinate pairs fall approximately within the right-hand half of the semi-elliptical domain identified in

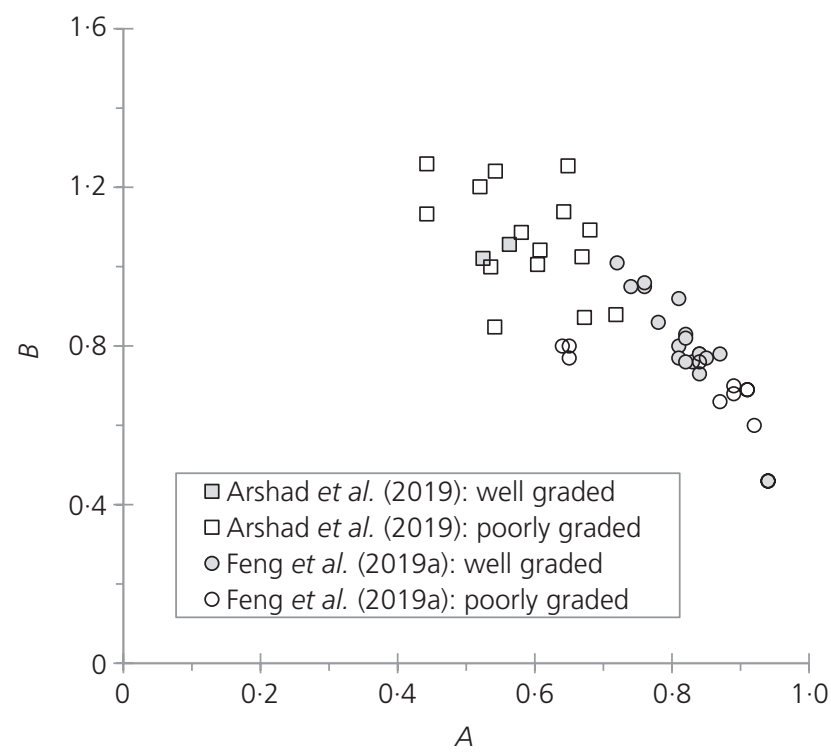

Figure 3. Variation in gradation, as expressed in terms of normalised entropy increment against relative base grading entropy for the investigated soils
Figure 1. In presenting the data points in Figure 3, the authors have distinguished between well-graded and poorly graded materials to allow for a more critical assessment of the data sets - that is, for gravel soils with $C_{\mathrm{C}}=1-3, C_{\mathrm{U}} \geq 4 \rightarrow$ well graded and $C_{\mathrm{U}}<4 \rightarrow$ poorly graded (ASTM, 2017), whereas $C_{\mathrm{C}} \neq 1-3 \rightarrow$ gap-graded soils. For sand soils, $C_{\mathrm{U}} \geq 6$ and $<6$ with $C_{\mathrm{C}}=1-3 \rightarrow$ well graded and poorly graded, respectively, whereas $C_{\mathrm{C}} \neq 1-3 \rightarrow$ gap graded (ASTM, 2017).

As evident from Figure 3 and noted previously by Feng et al. (2019b), the gradation characteristics of the gravel mixtures comprising data set $\mathrm{X}$ were such that their $B$ values negatively correlate with $A\left(R^{2}=0 \cdot 50\right)$, whereas only a weak correlation $\left(R^{2}=\right.$ $0 \cdot 16)$ occurs for data set $\mathrm{Y}$ - that is, the soil materials comprising data set $\mathrm{X}$ were mostly well graded, whereas those comprising data set $\mathrm{Y}$ were predominantly poorly graded.

\section{Correlations with $C_{U}$ and $C_{C}$}

The $C_{\mathrm{U}}$ and $C_{\mathrm{C}}$ values for the sandy soil samples (data set $\mathrm{Y}$ ) ranged $1 \cdot 60-12 \cdot 50$ and $0 \cdot 73-5 \cdot 12$, respectively, with $C_{\mathrm{U}}=$ $1 \cdot 51-7 \cdot 29$ and $C_{\mathrm{C}}=0 \cdot 62-3 \cdot 5$ for the gravel mixtures (data set $\mathrm{X}$ ). Feng et al. (2019a) reported that for data set X, $C_{\mathrm{U}}$ inversely correlated with coordinate $A$ and directly correlated with coordinate $B$. As evident from Figure 4, however, these trends are not obvious when considering the combined data sets $\mathrm{X}$ and $\mathrm{Y}$.

For data set X, 18 out of the 30 gravel mixtures investigated classify as well graded $\left(C_{U} \geq 4\right)$, compared with only two of the 17 sandy soil samples $\left(C_{\mathrm{U}} \geq 6\right)$ comprising data set $\mathrm{Y}$. It would appear that the above trends deduced by Feng et al. (2019a) for data set $\mathrm{X}$ arose on account of the data points associated with its 18 wellgraded gravels. As evident from Figures 4(c) and 4(d), the 20 wellgraded soils for the combined data sets $\mathrm{X}$ and $\mathrm{Y}$ exhibit reasonably strong correlations between $C_{\mathrm{U}}$ and the coordinates $A$ and $B\left(R^{2} \approx\right.$ $0 \cdot 64$ ), whereas $C_{\mathrm{U}}$ was independent of coordinates $A$ and $B$ for the 27 poorly graded sand and gravel materials.

In relation to $C_{\mathrm{C}}$, Feng et al. (2019a) observed that for data set X, higher values of $C_{\mathrm{C}}$ peaked around $A=0.82$ and $B=0.78$, which is generally evident for the combined data sets $\mathrm{X}$ and $\mathrm{Y}$ presented in Figure 5. This was also the case when the well-graded and poorly graded subsets of the combined data sets were investigated. It is concluded, however, that apart from $C_{\mathrm{U}}$ for the well-graded soils, neither $C_{\mathrm{U}}$ nor $C_{\mathrm{C}}$ is a candidate for useful correlations with the coordinates $A$ and (or) $B$.

\section{Correlations with $D_{10}$ and $D_{50}$}

Data sets $\mathrm{X}$ and $\mathrm{Y}$ reported $D_{10}$ and $D_{50}$ values for the investigated materials $(n=47)$, but only data set $\mathrm{Y}$ also reports $D_{30}$ and $D_{60}$. Considering the small sample size for the latter parameters $(n=$ 17), only the dependences of $D_{10}$ and $D_{50}$ on the coordinates $A$ and $B$ are investigated in the present study. For the $D_{10}-A, D_{10}-B$, $D_{50}-A$ and $D_{50}-B$ relationships, exponential fitting of the combined data sets (Equations 9-14) was found to produce marginally higher $R^{2}$ values compared with other forms of their relationships - that is, 


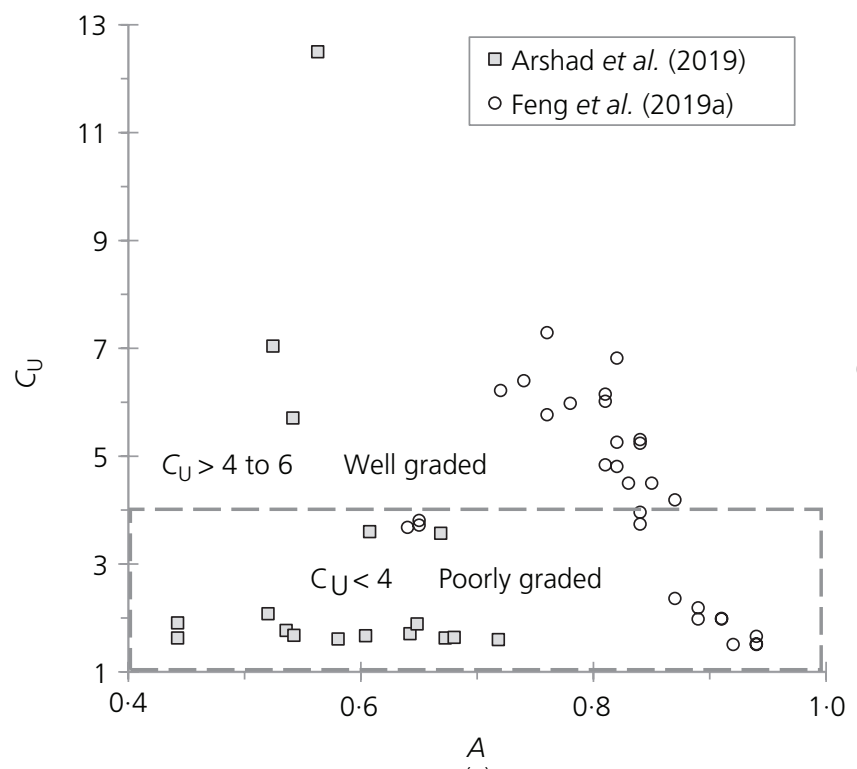

(a)

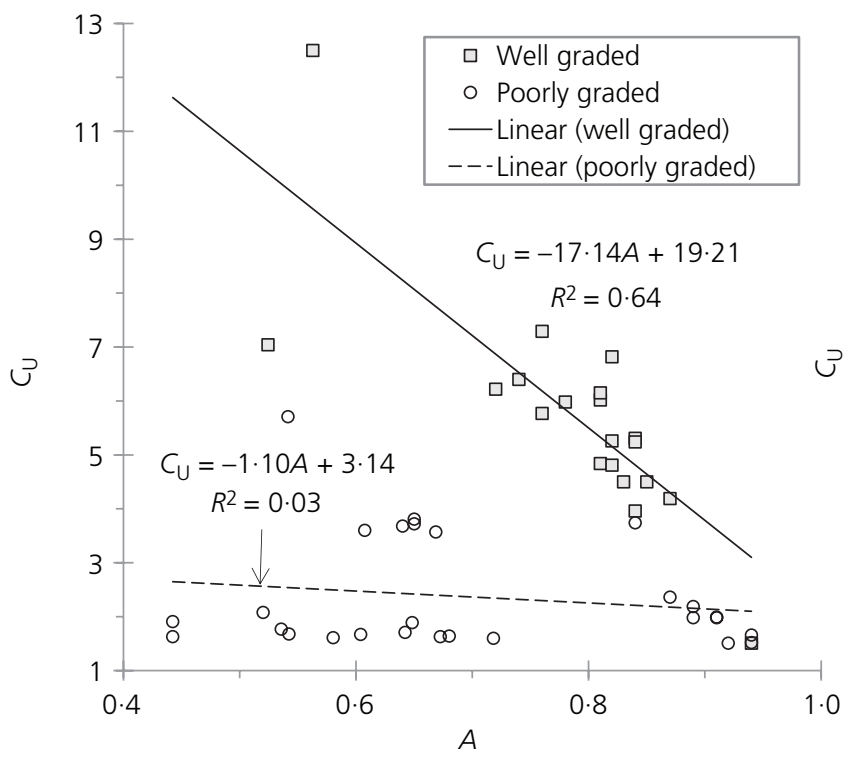

(c)

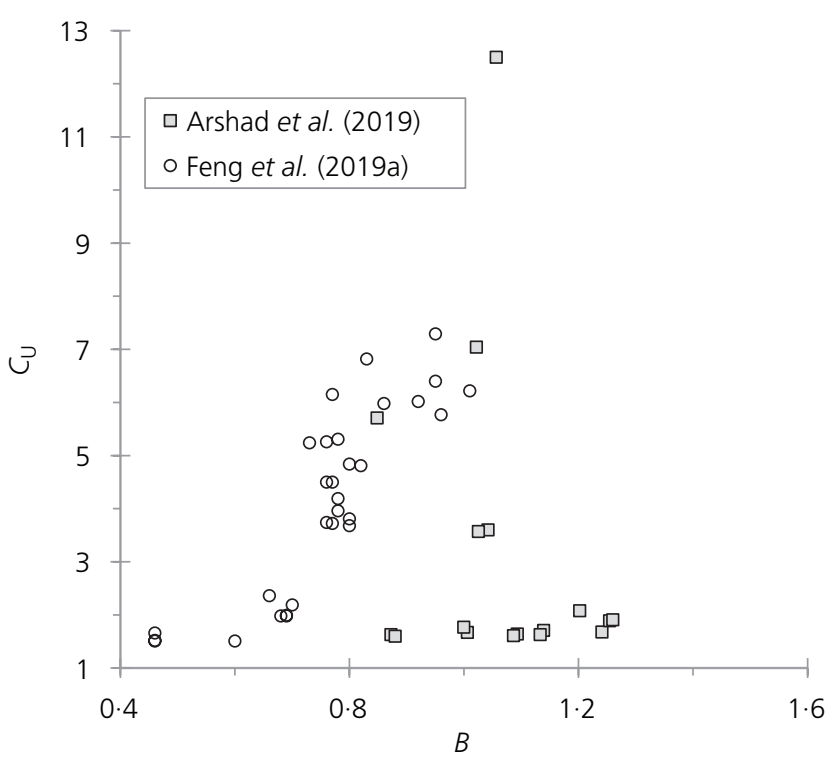

(b)

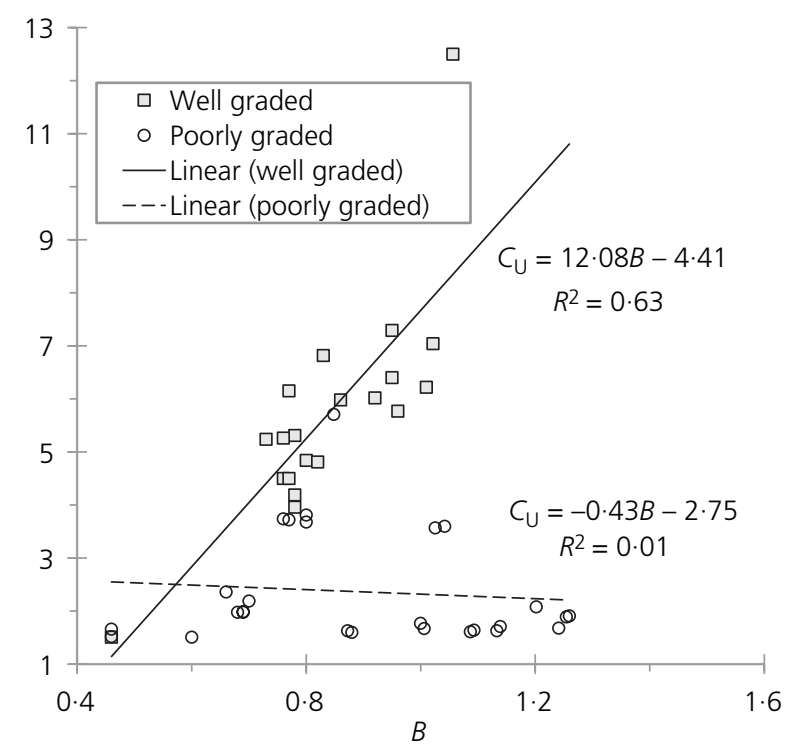

(d)

Figure 4. Dependence on the uniformity coefficient: (a) coordinate $A_{;}$(b) coordinate $B$; (c) considering gradation classification and coordinate $A$; (d) considering gradation classification and coordinate $B$

$\log D_{10}$ and $\log D_{50}$ both positively correlate with coordinate $A$ and negatively correlate with coordinate $B$ for these soils (Figure 6). Further, referring to Figures 6(a)-6(d), both $\log D_{10}$ and $\log D_{50}$ correlate more closely with coordinate $A\left(R^{2}=0.83\right.$ for both) than coordinate $B\left(R^{2}=0 \cdot 71\right.$ and $0 \cdot 67$, respectively).

$$
D_{10}(\mathrm{~mm})=2 \cdot 58 \times 10^{-4} e^{10 \cdot 67 A}
$$

9. $\left(R^{2}=0 \cdot 83, n=47\right)$

$$
D_{10}(\mathrm{~mm})=2 \cdot 92 \times 10^{2} e^{-6.98 B}
$$

10. $\left(R^{2}=0 \cdot 71, n=47\right)$

$$
D_{50}(\mathrm{~mm})=5 \cdot 07 \times 10^{-4} e^{11 \cdot 14 A}
$$

11. $\left(R^{2}=0 \cdot 83, n=47\right)$ 


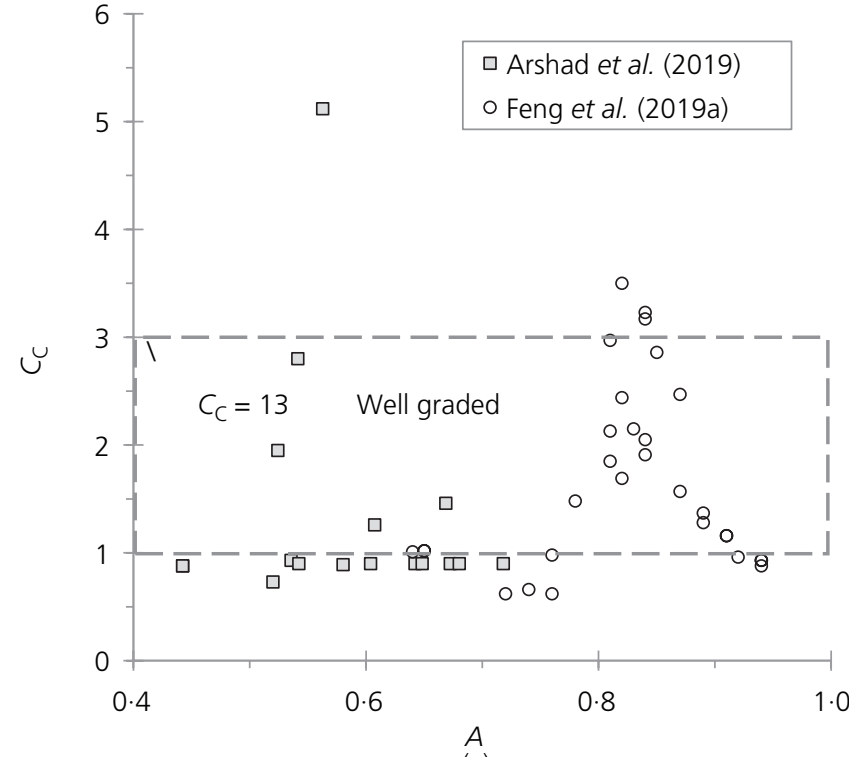

(a)

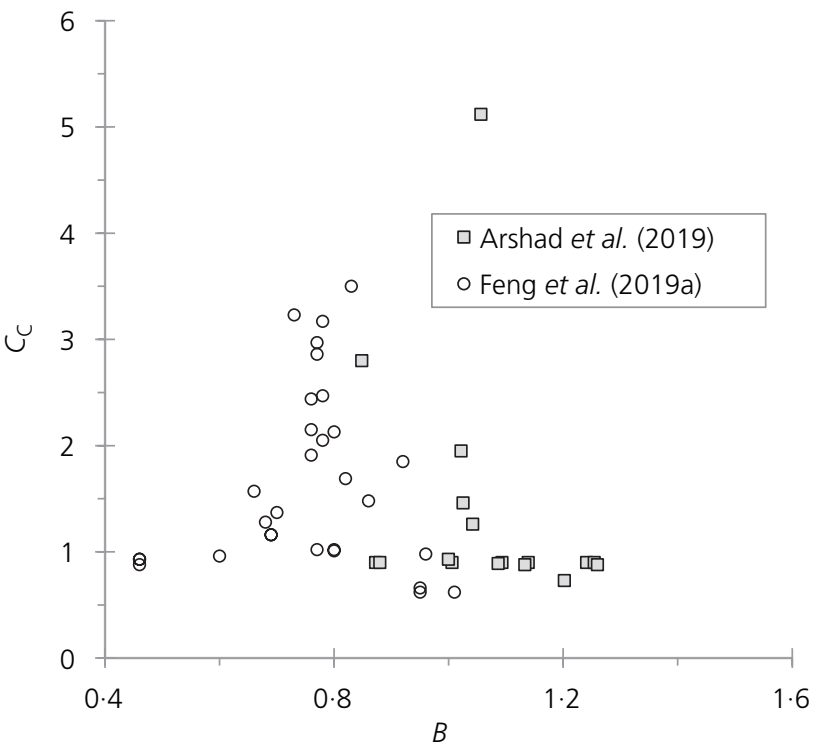

(b)

Figure 5. Dependence on the curvature coefficient: (a) coordinate $A$; (b) coordinate $B$

$$
D_{50}(\mathrm{~mm})=9 \cdot 03 \times 10^{2} e^{-7 \cdot 10 B}
$$

12. $\left(R^{2}=0 \cdot 67, n=47\right)$

Referring to Figures 6(e) and 6(f), the 20 well-graded soils for the combined data sets $\mathrm{X}$ and $\mathrm{Y}$ exhibit a very strong correlation between $\log D_{10}$ and the coordinate $A$ (Equation 13: $R^{2}=0.94$ ), compared with the moderately strong correlation obtained for the 27 poorly graded soils. Further, compared with the well-graded soils (Equation 14), the correlation between $\log D_{10}$ and coordinate $B$ was stronger for the poorly graded soils, possibly reflecting its measure of peakiness (kurtosis) of the PSD.

$$
D_{10}(\mathrm{~mm})=2.45 \times 10^{-5} e^{13.43 A}
$$

13. $\left(R^{2}=0 \cdot 94, n=20\right.$ : well-graded soils $)$

$$
D_{10}(\mathrm{~mm})=5 \cdot 07 \times 10^{2} e^{-7 \cdot 48 B}
$$

14. $\left(R^{2}=0 \cdot 57, n=20\right.$ : well-graded soils $)$

On first viewing of Figures 6(a)-6(f), there appears to be significant scatter in the data points for $D_{10}<\sim 1 \mathrm{~mm}$, but this follows directly from the logarithmic scale employed for the $y$-axis which always makes the points below 1.0 more dispersed (in the vertical axis), whereas it makes the points above 1.0 more concentrated (in the vertical axis). What is interesting is that the type of curve obtained will predict in a more accurate manner for small values of $D_{10}\left(D_{50}\right)$, increasing the prediction interval with larger $D_{10}\left(D_{50}\right)$. In the case of $D_{10}\left(D_{50}\right)-A$, this will occur for smaller values of coordinate $A(0 \cdot 4-0 \cdot 7)$, whereas in the case of $D_{10}\left(D_{50}\right)-B$, it will happen for large values of coordinate $B$ $(0 \cdot 8-1 \cdot 4)$ - that is, in the case of the data that the authors have and referring to the ranges of coordinates $A$ and $B$ for the two data sets shown in Figure 3 , the exponential $D_{10}\left(D_{50}\right)-A$ and $D_{10}\left(D_{50}\right)-B$ models will provide more accurate prediction for data set $\mathrm{Y}$ (sand and silty sand materials) compared with data set $\mathrm{X}$ (gravels).

\section{Correlations with permeability coefficient}

Figure 7 presents the measured permeability-coefficient $\left(k_{\mathrm{M}}\right)$ values plotted against the coordinate $A$ and $B$ values for the combined data sets $\mathrm{X}$ and $\mathrm{Y}$. As evident from this figure, $\log k_{\mathrm{M}}$ directly correlates with $\log A$ and inversely correlates with $\log B$. The $k_{\mathrm{P}}-A$ and $k_{\mathrm{P}}-B$ models for the combined data sets are presented as the following equations

$$
k_{\mathrm{P}}(\mathrm{m} / \mathrm{s})=7.84 \times 10^{-1} A^{16 \cdot 29}
$$

15. $\left(R^{2}=0 \cdot 83, n=47\right)$

$$
k_{\mathrm{P}}(\mathrm{m} / \mathrm{s})=4.96 \times 10^{-4} B^{-12.44}
$$

16. $\left(R^{2}=0 \cdot 68, n=47\right)$

From Figure 7, it could again be construed that considerably greater scatter in the data points occurs for data set Y (17 sandy soils), although this also arises from the representation, as explained earlier for Figures 6(a)-6(f). Note that here, as the scale is log-log, the 


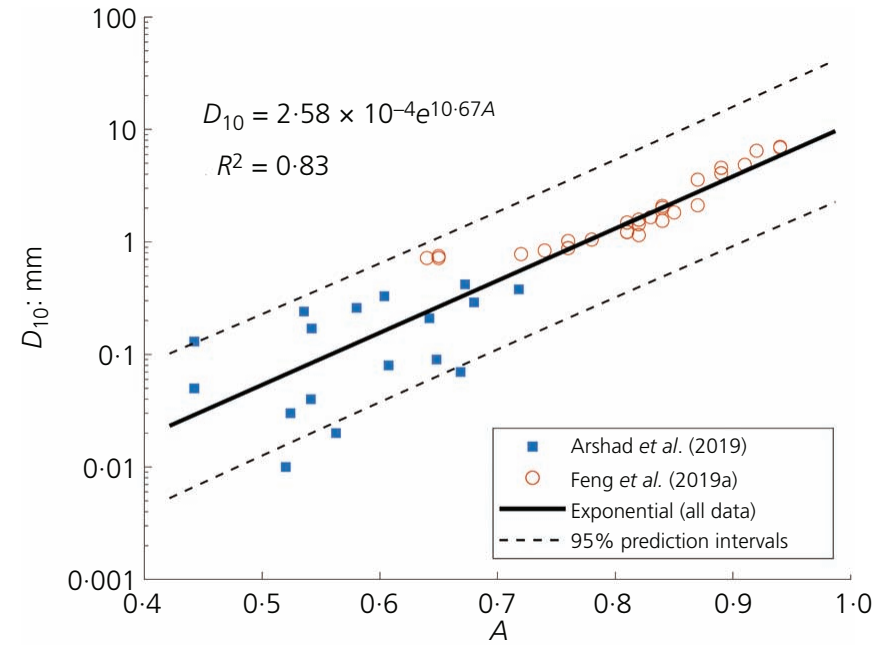

(a)

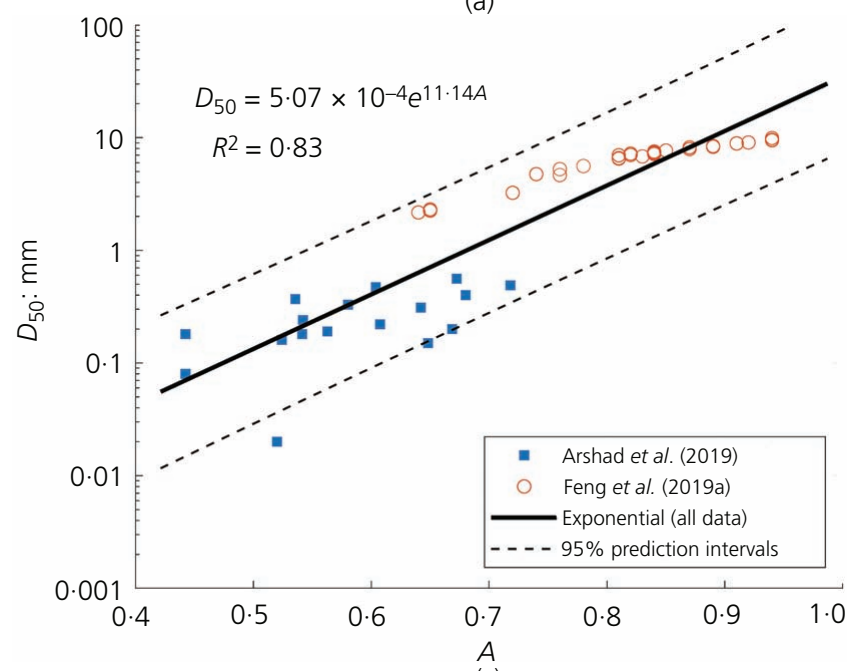

(c)

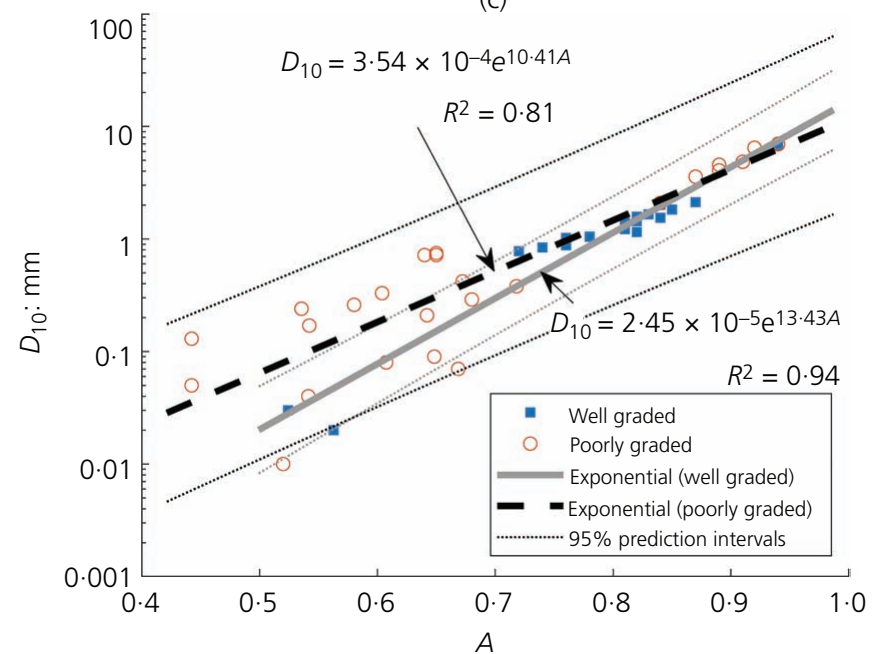

(e)

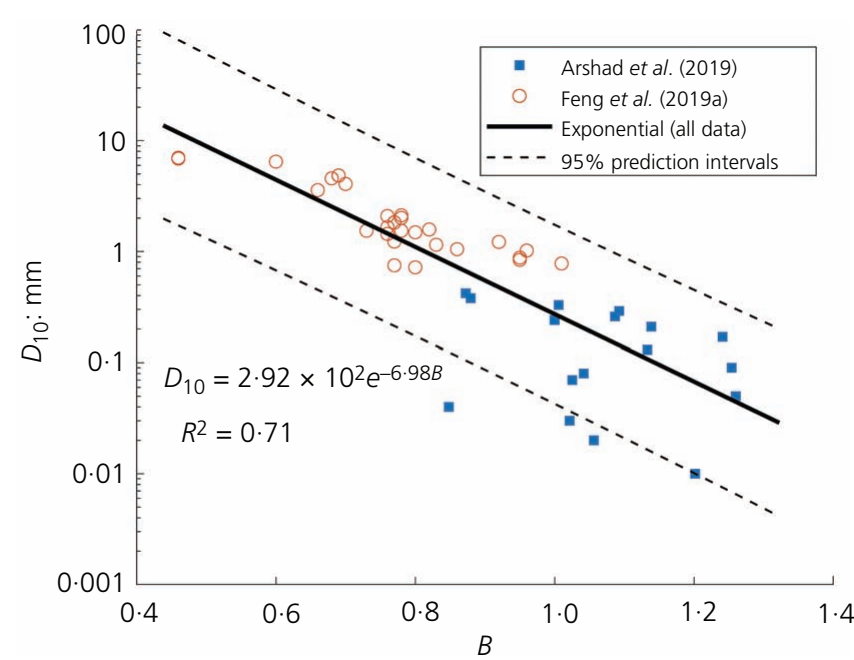

(b)

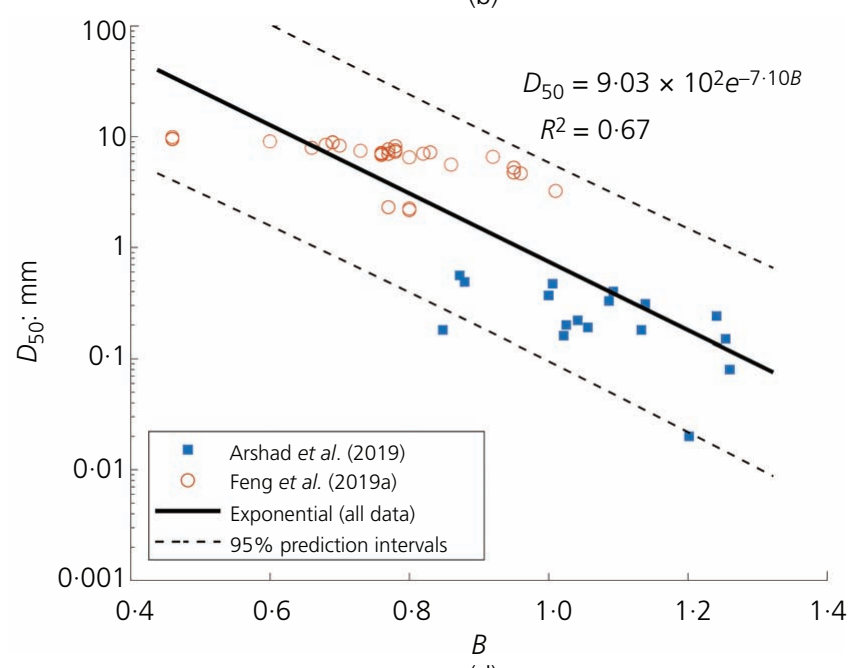

(d)

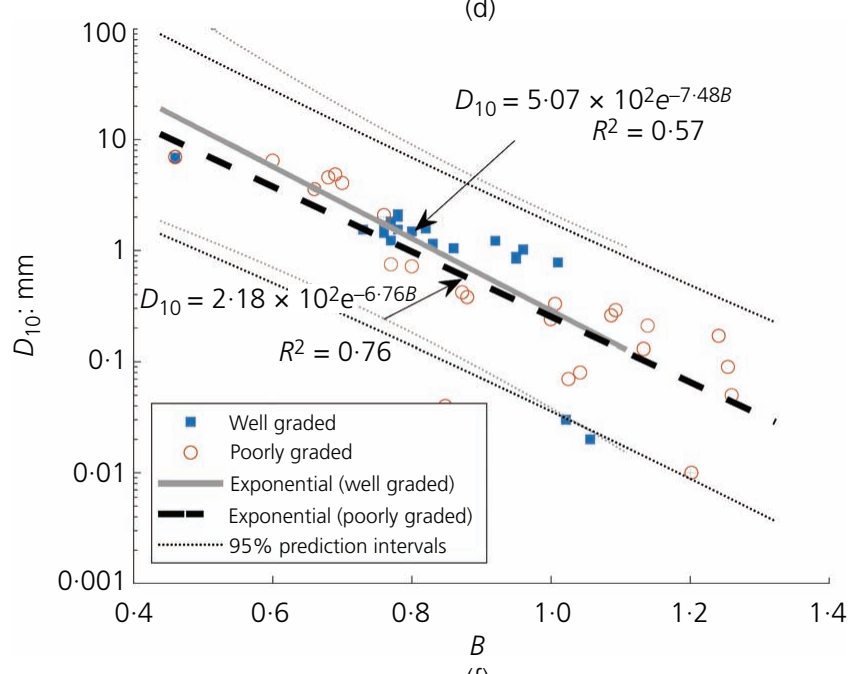

(f)

Figure 6. Dependence of grading entropy coordinates on $(\mathrm{a}, \mathrm{b})$ effective grain size, $D_{10} ;(\mathrm{c}, \mathrm{d})$ mean grain size, $D_{50}$; and $(\mathrm{e}, \mathrm{f}) D_{10}$ and soil gradation classification of well-graded and poorly graded 


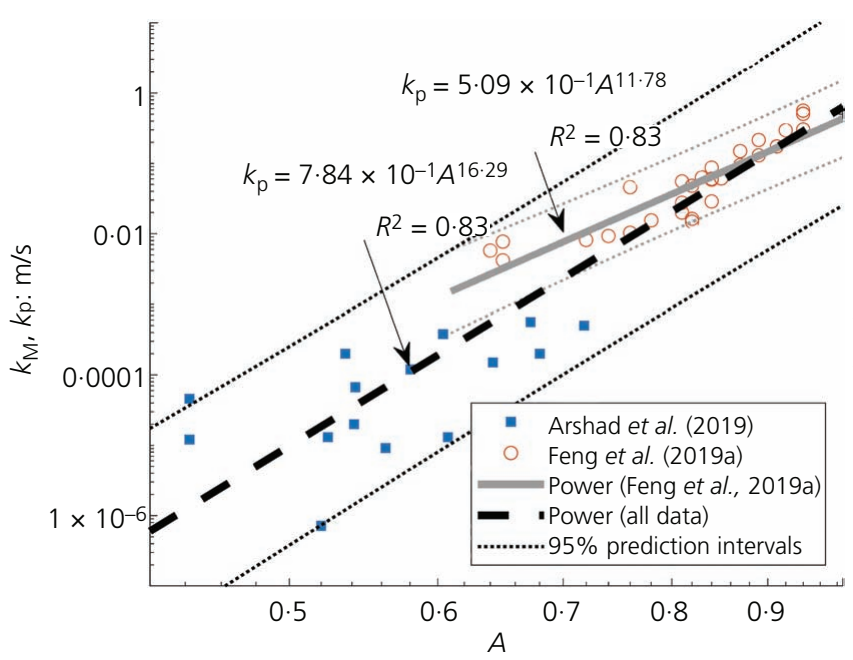

(a)

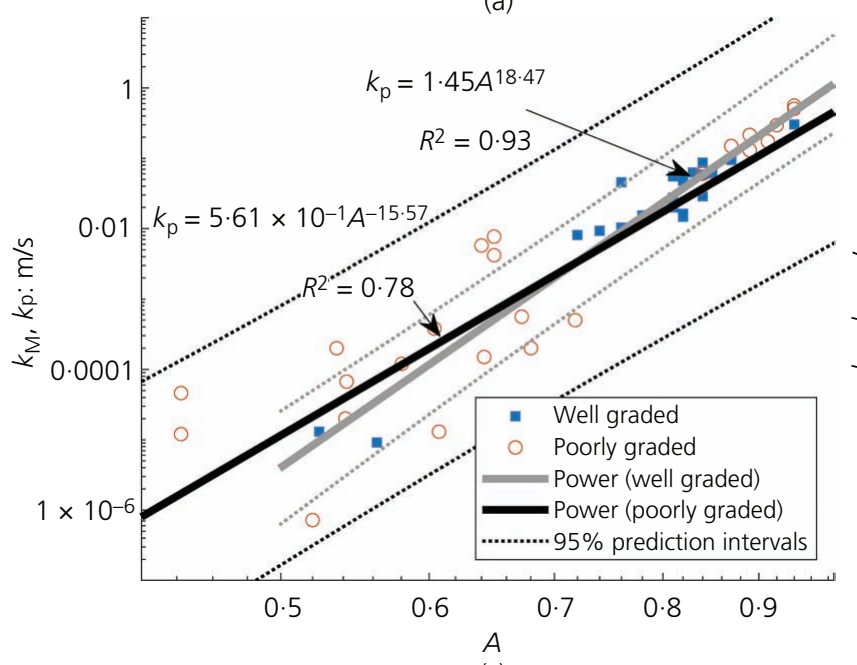

(c)

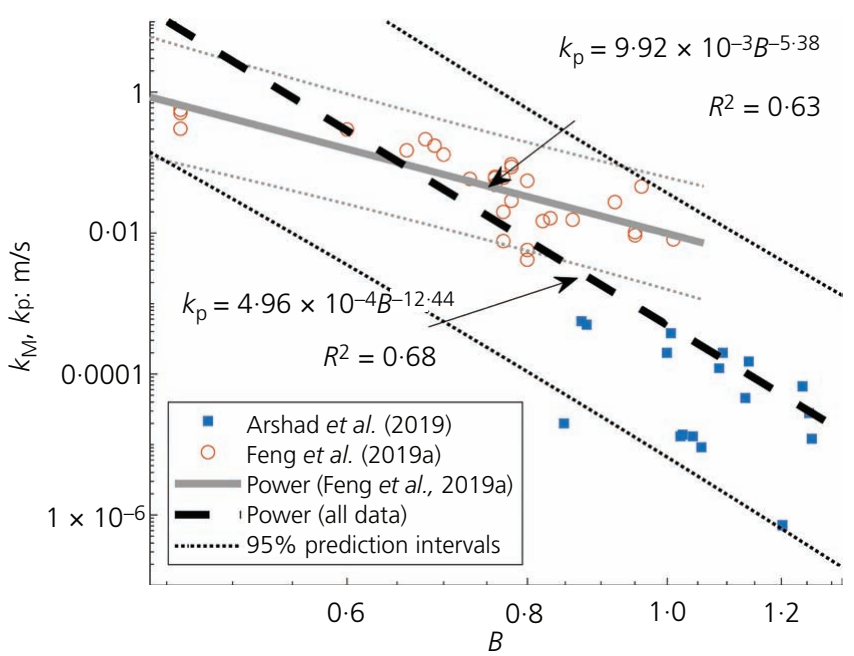

(b)

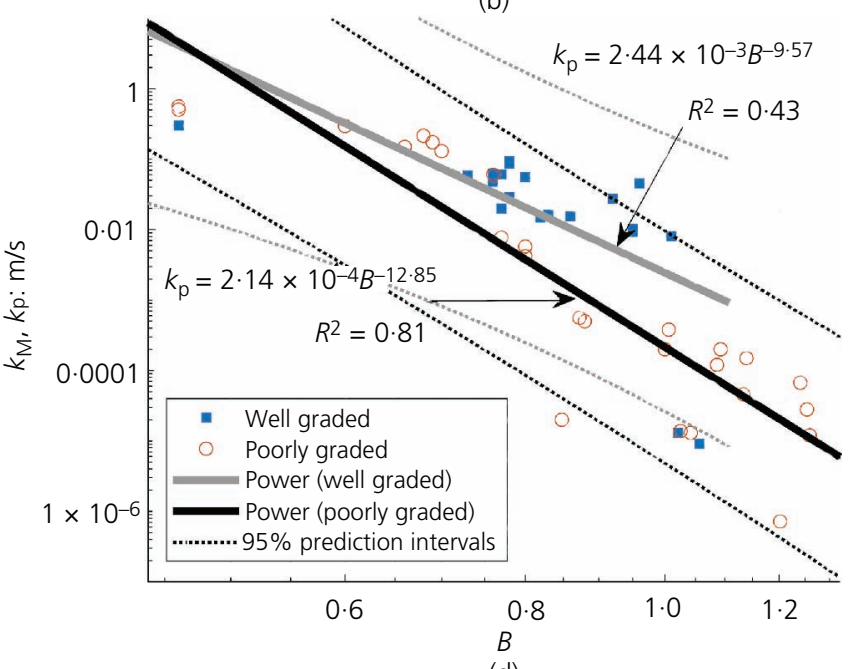

(d)

Figure 7. Dependence of $k_{\mathrm{M}}\left(k_{\mathrm{p}}\right)$ on grading entropy coordinates: (a) $A_{\text {; }}$ (b) $B$; (c) $A$ with consideration of gradation classification; (d) $B$ with consideration of gradation classification. Note: logarithmic scale used for $x$-axes

effect applies to both $x$ - and $y$-axes. Given the range of definition of coordinates $A$ and $B$, the dispersion effect is not so obvious in the $x$ axis. Similar to the $D_{10}\left(D_{50}\right)$ against $A$ and $B$ correlations small values of $k$ will be predicted with more precision. In the case of $A-k$, this will happen for smaller values of coordinate $A$. In the case of $B-k$, this will happen for larger values of coordinate $B$ - that is, again, data set $\mathrm{Y}$ (sand and silty sand materials) will be better predicted than data set $\mathrm{X}$ by this type of power equation.

Based on the regression results for the combined data sets (Figures 7(a) and 7(b)), compared with $\log B\left(R^{2}=0.68\right), \log A$ correlates more closely with $\log k_{\mathrm{M}}(0 \cdot 83)$. However, when the well-graded and poorly graded subsets were analysed separately (Figures 7(c) and 7(d)), the strongest correlations were found for well-graded soils between $\log k_{\mathrm{M}}$ and $\log A$ and for poorly graded soils between $\log k_{\mathrm{M}}$ and $\log B$ (see Equations 17 and 18, respectively). Again, this follows from the fact that coordinate $A$ reflects the skewness (symmetry) of the PSD, whereas coordinate $B$ measures the peakiness (kurtosis) of the distribution.

$$
k_{\mathrm{P}}(\mathrm{m} / \mathrm{s})=1 \cdot 45 A^{18 \cdot 47}
$$

17. $\left(R^{2}=0 \cdot 93, n=20\right.$ : well-graded soils $)$

$$
k_{\mathrm{P}}(\mathrm{m} / \mathrm{s})=2 \cdot 14 \times 10^{-4} B^{-12 \cdot 85}
$$

18. $\left(R^{2}=0 \cdot 81, n=27\right.$ : poorly graded soils $)$

Hence, it should follow that for well-graded coarse soils, a $k_{\mathrm{P}}-A$ power model will provide a more accurate prediction, whereas $k_{\mathrm{P}}-B$ or preferably $k_{\mathrm{P}}=f_{\mathrm{n}}(A, B)$ power models are more appropriate for their poorly graded counterparts. 


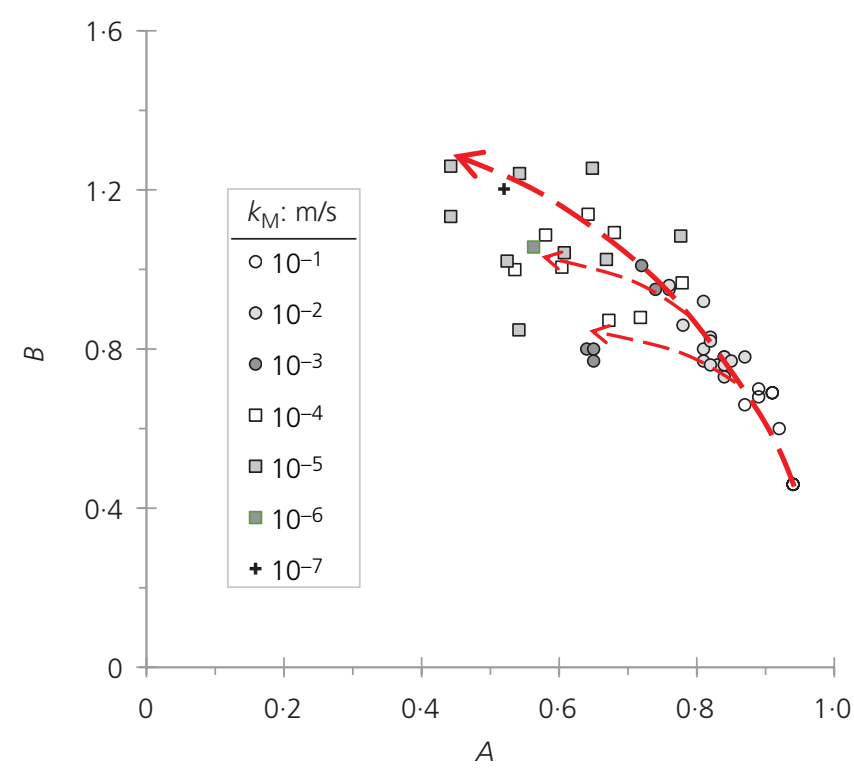

Figure 8. Trends of reducing $k_{\mathrm{M}}$ values indicated on grading entropy chart

The values of the grading entropy coordinate pairs for the 30 gravel and 17 sandy soil samples comprising data sets $\mathrm{X}$ and $\mathrm{Y}$ are plotted in Figure 8, with the associated order of magnitude of their $k_{\mathrm{M}}$ values indicated. With the values of the coordinate $A$ approximately ranging from 0.5 to unity, from the identified trends presented in this figure, the value of $k_{\mathrm{M}}$ reduces overall for decreasing $A$ and increasing $B$ (as per Equations 15 and 16). For $A<0 \cdot 5$, one could also anticipate that the value of $k_{\mathrm{M}}$ would reduce overall with $A$ decreasing and $B$ increasing in value. As suggested by Feng et al. (2019a), the form of presentation of the experimental data given in Figure 8 may be useful as a design chart for engineers to make deductive assessments of the tendency of coarse-grained soils to exhibit high or low $k$ values.

\section{Correlations with compacted void ratio}

In the case of data set $\mathrm{Y}$, the $60 \mathrm{~mm}$ dia. $\times \sim 150 \mathrm{~mm}$ high permeameter specimens were densified to achieve $94 \pm 3 \%$ of the SP-compaction maximum dry density value determined for the major constituting parent soil element. In contrast, for data set X, the $90 \mathrm{~mm}$ dia. $\times \sim 320 \mathrm{~mm}$ long permeameter specimens were comprised of four layers, each layer compacted manually by applying 70 blows using a sliding cylindrical tamper of $50 \mathrm{~mm}$ dia. and $2.5 \mathrm{~kg}$ self-weight to produce a compacted dry density of $\sim 1.572 \mathrm{Mg} / \mathrm{m}^{3}$. Since maximum and minimum void ratio values were not reported for the various materials investigated, it was not possible to perform analysis and evaluations based on the relative density and (or) at a particular dry density ratio, rather only in terms of the reported $e_{\text {compacted values. }}$

Compared with the 17 compacted sandy soil samples $(0 \cdot 34-0 \cdot 56)$, the void ratio values of the 30 compacted gravel mixtures $\left(e_{\text {compacted }}\right.$ $=0 \cdot 51-0 \cdot 85)$ were significantly greater. Using the combined data sets $\mathrm{X}$ and $\mathrm{Y}$, the linear, exponential and power correlations were investigated for the $A-e_{\text {compacted }}\left(R^{2}=0.77,0.75\right.$ and 0.72 , respectively) and $B-e_{\text {compacted }}\left(R^{2}=0.63,0.57\right.$ and 0.57 , respectively) relationships - that is, the normal $A-e_{\text {compacted }}$ and $B-e_{\text {compacted }}$ plots produced the strongest (linear) correlations, with $e_{\text {compacted }}$ positively correlating with $A$ and negatively correlating with $B$ (Figures 9(a) and 9(b) and Equations 19 and 20).

19. $e_{\text {compacted }}=0 \cdot 87 A-0.06 \quad\left(R^{2}=0 \cdot 77, n=47\right)$

20. $e_{\text {compacted }}=-0.56 B+1.07 \quad\left(R^{2}=0 \cdot 63, n=47\right)$

Similar to their dependences on $k_{\mathrm{M}}$ and $D_{10}$, when considering the combined data sets, coordinate $A\left(R^{2}=0 \cdot 77\right)$ appears to correlate more closely with $e_{\text {compacted }}$ than coordinate $B(0 \cdot 63)$. When the wellgraded and poorly graded subsets were analysed separately, as expected, the fitted $e_{\text {compacted }}-A$ correlations indicated that, overall, the compacted well-graded soils had a marginally lower void ratio: see trend-line equations given in Figure 9(c). Further, compared with the well-graded soils $\left(R^{2}=0 \cdot 47\right)$, a stronger correlation was obtained between $e_{\text {compacted }}$ and coordinate $B(0 \cdot 67)$ for the poorly graded soils, reflecting again the fact that coordinate $B$ measures the peakiness (kurtosis) of the distribution.

\section{Proposed updated grading entropy model}

This section proposes updated grading entropy permeabilityprediction models, incorporating the new insights gleaned from the detailed analyses of the published data sets presented in the previous sections. Specifically, the updated model should incorporate the void ratio parameter and consideration should be given to separate evaluations for well-graded and poorly graded soil materials. Following from the $k_{\mathrm{P}}-A$ and $k_{\mathrm{P}}-B$ power correlations deduced for well-graded and poorly graded coarsegrained soils given by Equations 17 and 18, respectively, it was postulated in the section headed 'Correlations with permeability coefficient' that for well-graded soils, a $k_{\mathrm{P}}-A$ power model may be adequate, whereas $k_{\mathrm{P}}-B$ or preferably $k_{\mathrm{P}}=f_{\mathrm{n}}(A, B)$ power models are more appropriate for their poorly graded counterparts. In general, a correlation of the form $k_{\mathrm{P}}=f_{\mathrm{n}}(A, B, e)$ should prove statistically superior and extend the model's scope and reliability, at least for assessments of a given material type with different densification levels. Based on various statistical analyses, the following improved grading entropy permeability-prediction model in which the void ratio is considered as an additional variable was proposed by the authors in the discussion paper by Feng et al. (2019)

21. $k_{\mathrm{P}}=C_{1} A^{C_{2}} B^{C_{3}} e^{C_{4}}$

where $C_{1}, C_{2}, C_{3}$ and $C_{4}$ are the fitting coefficients, with $C_{1}$ expressed in the same units as $k_{\mathrm{P}}$, whereas $C_{2}$ to $C_{4}$ are dimensionless. 


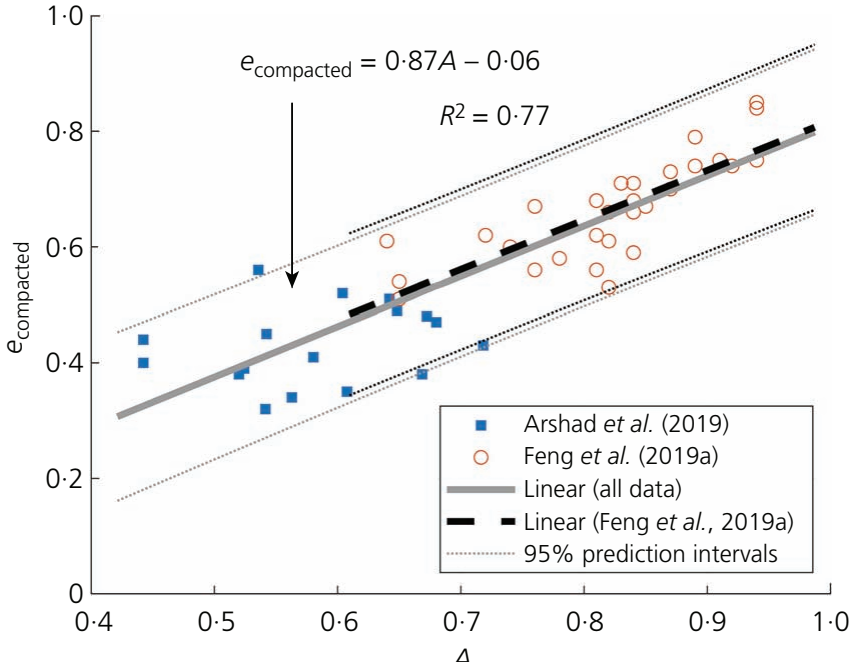

(a)

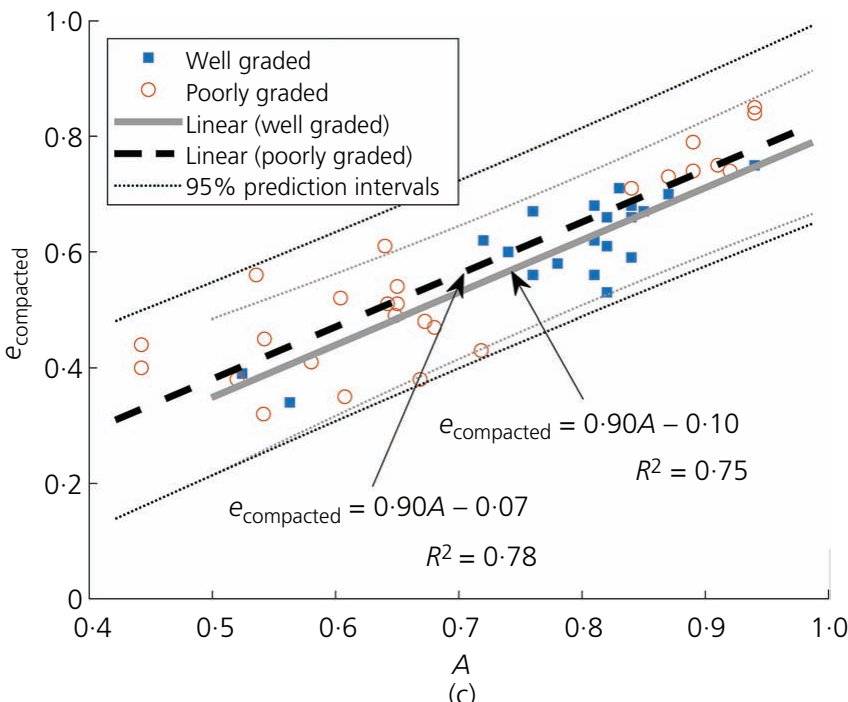

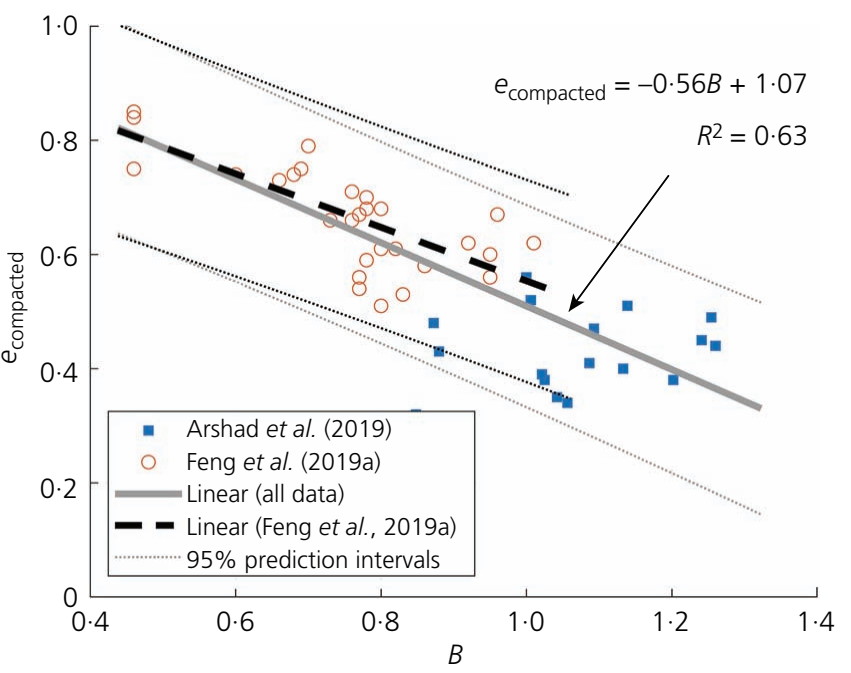

(b)

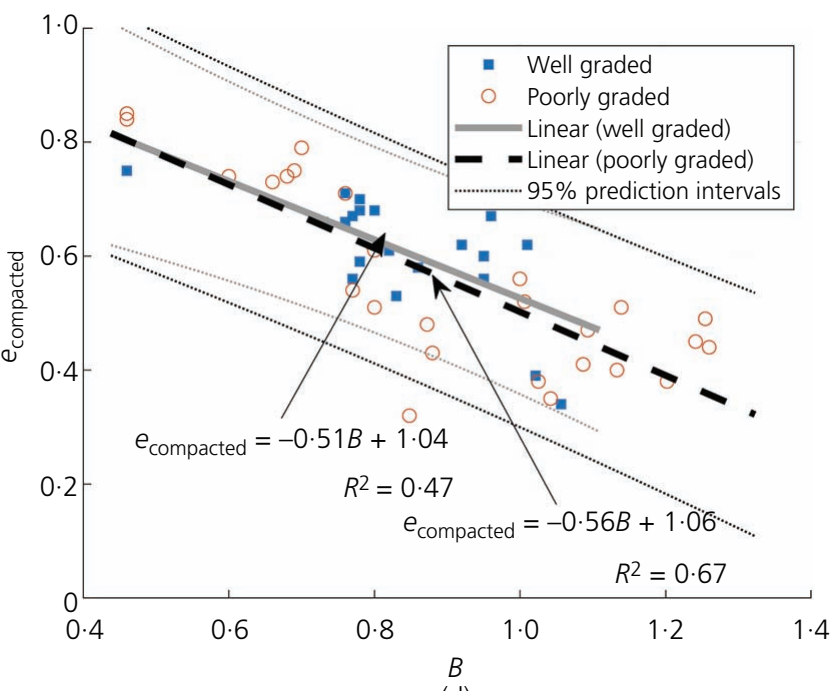

(d)

Figure 9. Dependence on compaction void ratio: (a) coordinate $A$; (b) coordinate $B$; (c) coordinate $A$ considering soil gradation; (d) coordinate $B$ considering soil gradation

The various grading entropy models described earlier were tested using the combined data sets $\mathrm{X}$ and $\mathrm{Y}$, and also considering their well-graded and poorly graded soil subsets, with the results presented in Table 2. In all cases, including a second and a third variable into the regression model improves the quality of the model, as shown by the adjusted $R^{2}$ (i.e. $R_{\mathrm{a}}^{2}$ ), which penalises the number of variables employed in the model. However, it could be argued that, overall, the fitting of the three-variable model $(A, B$, $e)$ is surprisingly good $\left(R^{2}=0.99\right)$. However, it could be argued that, overall, adding $B$ and the void ratio does not improve the

Table 2. Performance of various grading entropy permeability-prediction models for combined data sets $X$ and $Y$

\begin{tabular}{|c|c|c|c|c|c|}
\hline Data set & Model & Parameter value & \multicolumn{2}{|c|}{ Goodness of fit } & $p$-value \\
\hline Combined data sets $X$ and $Y(n=47)$ & $\begin{array}{c}k_{\mathrm{p}}=C_{1} A^{C_{2}} B^{C_{3}} \\
k_{\mathrm{p}}=C_{1} A^{C_{2}} B^{C_{3}} e^{C_{4}}\end{array}$ & $\begin{array}{c}C_{1}=0.10 \mathrm{~m} / \mathrm{s}, C_{2}=12.36, C_{3}=-4.17 \\
C_{1}=1.62 \mathrm{~m} / \mathrm{s}, C_{2}=5.65, C_{3}=-2.35, C_{4}=7.99\end{array}$ & $\begin{array}{l}R^{2}=0.86 \\
0.94\end{array}$ & $\begin{array}{l}R_{\mathrm{a}}^{2}=0.84 \\
0.93\end{array}$ & $\begin{array}{l}<0.0001 \\
<0.0001\end{array}$ \\
\hline \multirow[t]{2}{*}{ Well-graded soils $(n=20)$} & $k_{\mathrm{p}}=C_{1} A^{C_{2}}$ & $C_{1}=1.45 \mathrm{~m} / \mathrm{s}, C_{2}=18.47$ & 0.93 & 0.92 & $<0.0001$ \\
\hline & $\begin{array}{c}k_{p}=C_{1} A^{C_{2}} B^{C_{3}} \\
k_{p}=C_{1} A^{C_{2}} B^{C_{3}} e^{C_{4}}\end{array}$ & $\begin{array}{c}C_{1}=2.98 \mathrm{~m} / \mathrm{s}, C_{2}=20.07, C_{3}=1.68 \\
C_{1}=8.79 \mathrm{~m} / \mathrm{s}, C_{2}=11.41, C_{2}=1.10, C_{1}=6.51\end{array}$ & $\begin{array}{l}0.94 \\
0.99\end{array}$ & $\begin{array}{l}0.92 \\
0.98\end{array}$ & $\begin{array}{l}<0.0001 \\
<0.0001\end{array}$ \\
\hline \multirow[t]{3}{*}{ Poorly graded soils $(n=27)$} & $k_{p}=C_{1} B^{C_{3}}$ & $C_{1}=2.14 \times 10^{-4} \mathrm{~m} / \mathrm{s}, C_{2}=-12.85$ & 0.81 & 0.79 & $<0.0001$ \\
\hline & $k_{\mathrm{p}}=C_{1} A^{C_{2} B^{C_{3}}}$ & $C_{1}=8.14 \times 10^{-3} \mathrm{~m} / \mathrm{s}, C_{2}=7.53, C_{3}=-7.76$ & 0.87 & 0.84 & $<0.0001$ \\
\hline & $k_{p}=C_{1} A^{C_{2}} B^{C_{3}} e^{C_{4}}$ & $C_{1}=0.18 \mathrm{~m} / \mathrm{s}, C_{2}=2.34, C_{3}=-5.12, C_{4}=7.58$ & 0.95 & 0.93 & $<0.0001$ \\
\hline
\end{tabular}


quality of the prediction significantly, as the simple model (i.e. $\left.k_{\mathrm{P}}=C_{1} A^{C_{2}}\right)$ already provides a good fit $\left(R^{2}=0.93\right)$; whereas in the case of poorly graded soils, the three-variable model significantly improves the quality of the prediction $\left(R^{2}\right.$ increasing from $0 \cdot 81$ to $0 \cdot 95$ )

\section{Summary and conclusions}

The grading entropy framework provides a convenient means of presenting and interpreting the gradation characteristics of various soils. Further, the grading entropy approach provides a powerful tool for permeability-coefficient assessments of coarse-grained soils. From examination of the two published data sets comprising silty sand, sand and gravel materials, the compacted void ratio, $\log D_{10}$ and $\log D_{50}$ were found to correlate positively with coordinate $A$ and negatively correlate with coordinate $B$. Further, apparently stronger correlations occur for $A$ compared with $B$. For the well-graded soils subset, strong correlations were found between $C_{\mathrm{U}}$ and coordinates $A$ and $B$, and also between $\log D_{10}\left(\log D_{50}\right)$ and coordinate $A$. Consistent with these findings, $\log k_{\mathrm{M}}$ was found to correlate inversely with $\log B$ and correlate directly with $\log A$ and $e(\log e)$, such that for the investigated data sets, power functions of the form $k_{\mathrm{P}}=C_{1} A^{C_{2}} B^{C_{3}}$ and particularly $k_{\mathrm{P}}=C_{1} A^{C_{2}} B^{C_{3}} e^{C_{4}}$ proved statistically superior compared with other possible formulations.

Compared with the two-variable model $(A, B)$, the three-variable model (i.e. with the $e$ parameter included) gave a better fit to the experimental $k_{\mathrm{M}}$ values and has broader scope in terms of a wider application range of densification (compaction) states. Consideration should be given to separate evaluations for wellgraded and poorly graded soil materials. Note that the values of the fitting coefficients $C_{1}$ to $C_{4}$ determined from regression analysis are specific to the soil gradations and compaction levels investigated for the permeability tests - that is, the deduced correlations cannot be applied with confidence for dissimilar materials.

Further studies investigating a much larger database composed of more diverse sand and silty sand materials are recommended towards increasing the predictive power of the associated threevariable $(A, B, e)$ regression correlation. The inclusion of a particle shape factor and specific surface parameters in the upgraded three-variable model may possibly produce further performance enhancements.

\section{REFERENCES}

Arshad M, Nazir MS and O'Kelly BC (2019) Evolution of hydraulic conductivity models for sandy soils. Proceedings of the Institution of Civil Engineers - Geotechnical Engineering, https://doi.org/10.1680/ jgeen.18.00062

ASTM (2017) ASTM D 2487-17: Standard practice for classification of soils for engineering purposes (Unified Soil Classification System). ASTM International, West Conshohocken, PA, USA.

Carman PC (1937) Fluid flow through granular beds. Transactions of the Institution of Chemical Engineers 15: 150-166.

Carman PC (1939) Permeability of saturated sands, soils and clays. Agricultural Science 29(2): 263-273, https://doi.org/10.1017/ S0021859600051789.
Carrier WD III (2003) Goodbye, Hazen; hello, Kozeny-Carman. Geotechnical and Geoenvironmental Engineering 129(11) 1054-1056, https://doi.org/10.1061/(ASCE)1090-0241(2003)129:11 (1054).

Castillo E, Calviño A, Nogal M and Lo HK (2014a) On the probabilistic and physical consistency of traffic random variables and models. Computer-aided Civil and Infrastructure Engineering 29(7): 496-517, https://doi.org/10.1111/mice.12061.

Castillo E, O'Connor AJ, Nogal M and Calviño A (2014b) On the physical and probabilistic consistency of some engineering random models. Structural Safety 51: 1-12, https://doi.org/10.1016/j.strusafe.2014.05. 003.

Chapuis RP (2004) Predicting the saturated hydraulic conductivity of sand and gravel using effective diameter and void ratio. Canadian Geotechnical Journal 41(5): 787-795, https://doi.org/10. 1139/t04-022.

Chapuis RP (2012) Predicting the saturated hydraulic conductivity of soils: a review. Bulletin of Engineering Geology and the Environment 71(3): 401-434, https://doi.org/10.1007/s10064-012-0418-7.

Chapuis RP and Aubertin M (2003) On the use of the Kozeny-Carman equation to predict the hydraulic conductivity of soils. Canadian Geotechnical Journal 40(3): 616-628, https://doi. org/10.1139/t03-013.

Feng S, Vardanega PJ, Ibraim E, Widyatmoko I and Ojum C (2018a) Assessing the hydraulic conductivity of road paving materials using representative pore size and grading entropy. ce/papers 2(2-3): 871-876, https://doi.org/10.1002/cepa.780.

Feng S, Vardanega PJ and Ibraim E (2018b) Comparison of prediction models for the permeability of granular materials using a database. In Contemporary Issues in Soil Mechanics: Proceedings of the 2nd GeoMEast International Congress and Exhibition on Sustainable Civil Infrastructures, Egypt 2018 (Hemeda S and Bouassida M (eds)). Springer, Cham, Switzerland, pp. 1-13.

Feng S, Vardanega PJ, Ibraim E, Widyatmoko I and Ojum C (2019a) Permeability assessment of some granular mixtures. Géotechnique 69(7): 646-654, https://doi.org/10.1680/jgeot.17.T.039.

Feng S, Vardanega PJ, Ibraim I et al. (2019b) Discussion: Permeability assessment of some granular mixtures. Géotechnique, https://doi.org/ 10.1680/jgeot.19.D.005.

Imre E, Lörincz J and Rózsa P (2008) Characterization of some sand mixtures. In 12th International Conference on Computer Methods and Advances in Geomechanics 2008 (Jadhav MN (ed.)). Curran Associates, Red Hook, NY, USA, vol. 3, pp. 2064-2075.

Imre E, Lörincz J, Szendefy J et al. (2012) Case studies and benchmark examples for the use of grading entropy in geotechnics. Entropy 14(6): 1079-1102, https://doi.org/10.3390/e14061079.

Kozeny J (1927) Über kapillare leitung des wassers im boden (Aufstieg, versickerung und anwendung auf die bewässerung). Akademie der Wissenschaften in Wien Sitzungsber 136(2a): 271-306 (in German).

Lörincz J (1986) Grading Entropy of Soils. PhD thesis, Technical University of Budapest, Budapest, Hungary (in Hungarian).

Lörincz J, Imre EM and Singh VP (2017) The grading entropy-based criteria for structural stability of granular materials and filters. In Granular Materials (Sakellariou M (ed.)). IntechOpen, London, UK, pp. 161-182.

McDougall JR, Imre E, Barreto D and Kelly D (2013) Volumetric consequences of particle loss by grading entropy. Géotechnique 63(3): 262-266, https://doi.org/10.1680/geot.SIP13.T.002.

O'Kelly BC (2005) Consolidation properties of a dewatered municipal sewage sludge. Canadian Geotechnical Journal 42(5): 1350-1358, https://doi.org/10.1139/t05-054.

O'Kelly BC (2006) Compression and consolidation anisotropy of some soft soils. Geotechnical and Geological Engineering 24(6): 1715-1728, https://doi.org/10.1007/s10706-005-5760-0. 
Geotechnical Research

Volume 7 issue 1
Determination of soil permeability

coefficient following an updated grading

entropy method

O'Kelly and Nogal
O'Kelly BC (2008) Development of a large consolidometer-permeameter apparatus for testing soft soils. In Proceedings of GeoCongress 2008: Characterization, Monitoring and Modeling of GeoSystems

(Alshawabkeh AN, Reddy KR and Khire MV (eds)). American Society of Civil Engineers, Reston, VA, USA, GSP 179, vol. 5, pp. 60-67.

O'Kelly BC (2009) Development of a large consolidometer apparatus for testing peat and other highly organic soils. SUO - Mires and Peat 60(1-2): 23-36.
O'Kelly BC (2016) Briefing: Laboratory permeability determinations for biosolids. Environmental Geotechnics 3(3): 132-139, https://doi.org/ 10.1680 /jenge. 15.00026 .

Shannon CE (1948) A mathematical theory of communication. Bell System Technical Journal 27(3): 379-423, https://doi.org/10.1002/j. 1538-7305.1948.tb01338.x.

Singh VP (2014) Entropy Theory in Hydraulic Engineering: an Introduction. American Society of Civil Engineers, Reston, VA, USA.

\section{How can you contribute?}

To discuss this paper, please submit up to 500 words to the editor at journals@ice.org.uk. Your contribution will be forwarded to the author(s) for a reply and, if considered appropriate by the editorial board, it will be published as a discussion in a future issue of the journal. 